\title{
PENGARUH LEADER MEMBER EXCHANGE (LMX) DAN KEPUASAN KERJA TERHADAP PRODUKTIVITAS GURU PADA SEKOLAH DASAR SWASTA KATOLIK DI WILAYAH JAKARTA PUSAT
}

\begin{abstract}
Hermania Bhoki*
Abstract: The objective of this research was to understand the effect of Leader Member Exchange (LMX and job satisfaction on productivity. It was a quantitative research was conducted in sixteen schools located in Jakarta Centre. The research uses a survey method with path analysis was applied in testing hypothesis. It was conducted to 153 Teachers at Private Catholic Elementary Schools as the respondents which were selected in a simple random way. The result of this study are: (1). There is a positive direct effect of Leader Member Exchange (LMX) on productivity. (2). There is a positive direct effect of job satisfaction on productivity, and (3). There is a positive direct effect of Leader Member Exchange (LMX) on job satisfaction.
\end{abstract}

Keywords: Leader Member Exchange (LMX), job satisfaction, productivity.

\section{PENDAHULUAN}

Filosofi dan spirit tentang produktivitas terletak pada upaya manusia untuk mendapatkan hasil kerja sebanyak-banyaknya dan meningkatkan mutu kehidupan. Produktivitas merupakan indikator dari kinerja yang tinggi dari individu, tim dan organisasi. Sebuah organisasi yang memiliki produktivitas yang tinggi adalah organisasi profesional yang dapat mendayagunakan dan mengelolah sumber daya manusia dalam organisasi secara efektif dan efisien sehingga dapat memiliki kinerja yang tinggi dan pada akhirnya dapat meningkatkan produktivitas. Dalam organisasi pendidikan, sekolah mesti memiliki guru yang berproduktivitas tinggi sehingga dapat menjadikan sekolah tersebut menjadi lembaga pendidikan yang berkualitas yang dapat menjadi penyedia jasa layanan pendidikan yang bermutu bagi para pelanggan sesuai dengan tuntutan perubahan global.

Namun kualitas pendidikan di Indonesia masih memiliki mutu yang rendah. Penyebab rendahnya mutu pendidikan tersebut tentu tidak lepas dari peran guru sebagai ujung tombaknya. Berbagai media memberitakan bahwa problem kualitas pendidikan itu terkait langsung dengan kurangnya sumber daya guru yang menjadi salah satu sorotan utama ketika produktivitas sebuah sekolah mengalami kemunduran. Berita dari berbagai media itu antara lain; 1) Pada hari selasa, 17 April 2012, Yovita Arika menuliskan bahwa, Indeks Pembangunan Manusia Indonesia sangat rendah karena berada di urutan 124 dari 187 negara pada tahun 2011. Peringkat ini justru mengalami penurunan dari urutan ke 108 pada tahun 2010. (nasional. kompas.com) (2012). 2) Pada tanggal 24 Juli 2014, Djibril Muhammad menulis bahwa peringkat IPM Indonesia tetap berada pada posisi stagnan yakni urutan ke 108. (perdesaansehat.com) (2014). 3) Istamar Syamsuri, dalam tulisannya tentang The Indonesian Network of Higher Educations of Mathematics and Nanutal Sciences menyatakan bahwa; a) “...dari 146.052 SD di Indonesia, ternyata hanya 8 (delapan) SD saja yang mendapat pengakuan dunia dalam kategori The Prymary Year Program (PYP)". b) "...masih banyak guru yang belum professional". (respository. Upi.edu) (2012). 4) Rusyan dan Suherian dalam buku tentang membangun

* Dosen Teologi di Sekolah Tinggi Pastoral Reinha Larantuka-Flores-NTT. 
guru yang berkualitas menuliskan bahwa, "Menteri Pendidikan dan Kebudayaan merasa kecewa dengan nilai Uji Kompetensi Akhir (UKA) guru tahun 2012 yang cukup rendah dengan rata-rata secara nasional hanya mencapai 42,25\% saja". Ini berarti “...profesional guru mengalami kemerosotan yang mengkhawatirkan". (Rusyan dan Suherian: 2012). 5) Kepala Pembangunan Sumber Daya Manusia untuk Bank Dunia di Indonesia, Asia Timur dan Pasifik, Ma Chu Chang mengatakan bahwa, “... nilai terendah diperoleh guru SD (42,05)". Ini berarti kualitas dan kompetensi guru SD masih perlu dipertanyakan. (www.srie.org) (2013). 6) Terkait permasalahan ini, Ketua Tim Kerja Sekolah Dasar Majelis Pendidikan Katolik Wilayah Jakarta Pusat menginformasikan bahwa kurangnya produktivitas guru Sekolah Dasar dalam wilayah tersebut telah mengakibatkan kurangnya kualitasnya lulusan SD sehingga menyebabkan masyarakat kurang berminat menyekolahkan anaknya pada sekolah-sekolah tersebut tetapi beralih memilih sekolah negeri dan sekolah swasta lainnya. Akibatnya Sekolah-sekolah tersebut kekurangan murid tahun-tahun terakhir ini. (Informasi diperoleh dari, Ketua Tim Kerja Sekolah Dasar Majelis Pendidikan Katolik Wilayah Jakarta Pusat, pada 3 November 2014). 7) Tentang sekolah swasta kekurangan murid, Lenterakecil.com menulis bahwa, “...beberapa tahun terakhir ini sering muncul pemberitaan Sekolah Swasta kekurangan siswa bahkan terjadi penutupan karena jumlah siswa yang minim bahkan bisa dikatakan tidak punya siswa". Salah satu cara yang dapat dilakukan untuk mengatasi problem ini adalah dengan meningkatkan kualitas lulusan. (Lenterakecil.com) (2013). Peraturan Pemerintah no. 74 tahun 2008 tentang Guru menegaskan bahwa untuk memiliki kualitas lulusan yang baik, sekolah harus memiliki guru yang profesional. (eprints.undip.ac.id/234/1/pp-no-74-tahun-2008).

Jawaban atas masalah ini dapat diupayakan dengan membangun kualitas Leader Member Exchange (LMX) yakni hubungan dua arah yang positif antara kepala sekolah dengan guru untuk meningkatkan kesuksesan sekolah berdasarkan sikap saling menghormati kemampuan, saling percaya, dan saling memenuhi kewajiban satu sama lain. Kualitas hubungan yang positif tersebut menyebabkan para guru memiliki komitment kerja yang tinggi.untuk mencapai tujuan sekolah. Dengan begitu, mereka dapat menerima gaji yang lebih tinggi sehingga mereka dapat merasa puas terhadap pekerjaan mereka. Dengan kepuasan kerja yang tinggi, mereka dapat mengerahkan seluruh kemampuan mereka untuk bekerja keras memenuhi target-target pekerjaan yang diberikan dan yang menjadi tanggungjawab mereka secara efektif dan efisien, sehingga mereka dapat mencapai produktivitas kerja yang tinggi pula.

Berdasarkan uraian dalam latar belakang masalah di atas peneliti perlu melakukan kajian tentang Pengaruh Leader Member Exchange (LMX) dan Kepuasan Kerja Terhadap Produktivitas Guru, pada Sekolah Dasar Swasta Katolik di wilayah Jakarta Pusat.

\section{Produktivitas}

Menurut Ivancevich, Konopaske dan Matteson (2008:26) berpendapat, "productivity is the relationship between inputs (e.g., hour of work, effort, use of equipment) and output (e.g., personal computer product, customer complaints handled). The measures of productivity such as profit, sales, market share student graduated, patient released, documents processed, clients service, and the like". Produktivitas adalah hubungan antara masukan (seperti, jumlah jam kerja, usaha, penggunaan peralatan) dan keluaran (seperti; produksi, penanganan komplain pelanggan). Ukuran produktivitas mencakup profit, penjualan, lulusan siswa, proses dokumen, jasa pelanggan dan sebagainya. Hess dan 
Orthmann (2012: 463), menjelaskan, "productivity is converting resources to achieve results efficiently and effectively. Productivity measures results gained from a specific amount of effort. An efficient use of resources alone may not be effective or meet a desired need. An effective use of resources may not be efficient or sufficient in overall impact. Productivity planning helps balance efficiency and effectiveness guided by an overall desire for value". Produktivitas adalah konversi sumber daya untuk mencapai hasil secara efisien dan efektif. Produktivitas mengukur perolehan hasil yang spesifik dari sejumlah usaha. Perencanaan dan penggunaan sumber daya yang efisien dan efektif secara seimbang dapat berdampak pada nilai produktivitas secara keseluruhan. Allen, Plunkett, Attner (2013: 130) mengatakan, productivity is the relationship between the amount of input needed to produce a given amount of output and the output it self. Productivity is usually expressed as the ratio of inputs to outputs. Output (inputs produce)/Input (hours of human labor, machining time, or dollar invested $)=$ Productivity Index (PI). Such a ratio is a measure of efficiency that can be used to make comparisons and indentify trends. Productivity can be improve by increasing the amount of output generated by a fixed amount of input, or reducing the amount of input required to generate a fixed amount of output or a combination of both approaches. Produktivitas adalah hubungan antara jumlah masukan yang diperlukan untuk menghasilkan sejumlah output tertentu. Produktivitas biasanya dinyatakan sebagai rasio input ke output. Output (input produksi)/input (jam kerja manusia, waktu, atau dolar yang diinvestasikan) $=$ Indeks Produktivitas $(\mathrm{PI})$. Rasio tersebut adalah suatu ukuran efisiensi yang dapat digunakan untuk membuat perbandingan dan mengidentifikasi hal-hal yang dapat meningkatkan jumlah output yang dihasilkan oleh jumlah yang tetap dari input, atau mengurangi jumlah input yang diperlukan untuk menghasilkan jumlah yang tetap produksi atau kombinasi dari kedua pendekatan tersebut. Sedarmayati (2009: 56-57), mendefinisikan produktivitas berdasarkan formulasi dari National Productivity Board (NPB) Singapore sebagai sikap mental (attitude of mind) yang mempunyai semangat untuk melakukan peningkatan perbaikan dalam berbagai kegiatan, a) yang berkaitan dengan diri sendiri dapat dilakukan melalui peningkatan: pengetahuan, keterampilan, disiplin, upaya pribadi, dan kerukunan kerja. b) yang berkaitan dengan pekerjaan, dapat dilakukan melalui: manajemen dan metode kerja yang lebih baik, penghematan biaya, ketepatan waktu, sistem dan teknologi yang lebih baik.

Berdasarkan konsep yang telah dikemukakan di atas, maka dapat disintesiskan bahwa produktivitas ialah pencapaian target kerja yang maksimal yang diukur dengan mempertimbangkan dimensi efektivitas dan efisiensi dengan indikator: (1) ketepatan pencapaian tujuan, (2) ketepatan penggunaan metode, (3) ketepatan penggunaan waktu.

\section{Leader Member Exchange (LMX)}

Menurut, Achua dan Lussier (2013: 228) mendefinisikan, "Leader Member Exchange is define as the quality of the exchange relationship between a leader and follower." Pertukaran antara pemimpin dan anggota didefinisikan sebagai kualitas hubungan pertukaran antara pemimpin dan pengikut. Hsieh (www.wiete.com.au/journals) (2012) mendefinisikan, "LMX is defined as the quality of the exchange between a leader and their subordinates, which means that supervisors and subordinates establish mutual relationship and develop the level of mutual respect and trust". LMX didefinisikan sebagai kualitas pertukaran antara pemimpin dan bawahan memiliki arti bahwa atasan dan bawahan membangun hubungan timbal balik dan mengembangkan tingkat saling menghormati dan saling percaya. Rastgar, Pourebrahimi, Davoudi (www.pbr.co.in) (2012) menjelaskan, Leader-Member Exchange Theory (LMX) is a leadership theory that focuses on the 
two-way relationship between a supervisor (manager) and each of their subordinates (employees) and contributes to increasing organizational success by creating positive relations between the leader and subordinate. Teori Leader Member Exchange (LMX) adalah teori kepemimpinan yang berfokus pada hubungan dua arah antara atasan (manajer) dan masing-masing bawahan (karyawan) memberikan kontribusi untuk meningkatkan keberhasilan organisasi dengan menciptakan hubungan positif antara pemimpin dan bawahan. Yukl (2010: 122) juga mengatakan, "Leader-Member Exchange theory describes the role-making processes between a leader and each individual subordinate and the exchange relationship that develops over time." Teori pertukaran antara pemimpin - anggota menjelaskan tentang pembuatan peran di antara satu pemimpin dan masing-masing orang bawahan yang melampaui batas waktu. Menurut Graen dan Uhl-Bien, (mario.gsia.cmu.edu), (1995), menegaskan, "development of LMX is based on the characteristics of the working relationship as opposed to a personal or friendship relationship, and this trust, respect, and mutual obligation refer specifically to the individuals' assessments of each other in terms of their professional capabilities and behaviors. LMX dapat dibangun oleh pemimpin dan anggota dalam relasi kerja berdasarkan rasa percaya, sikap hormat kepada kemampuan profesional dan kewajiban timbal balik satu sama lain.

Dari rangkaian penjelasan tersebut, dapat disintesiskan bahwa LMX adalah hubungan dua arah yang positif antara pemimpin dan anggota yang bertujuan untuk meningkatkan kesuksesan organisasi dengan indikator: (1) saling menghormati kemampuan satu sama lain, (2) saling percaya, dan (3) saling memenuhi kewajiban.

\section{Kepuasan Kerja}

Menurut Newstrom (2011: 220), "job satisfaction is a set of favorable or unfavorable feelings and emotions with which employees view their work." Kepuasan Kerja adalah sekumpulan perasaan atau emosi menyenangkan atau tidak menyenangkan yang dirasakan karyawan terhadap pekerjaannya. Kreitner dan Kinicki (2010: 170), menguraikan, "job satisfaction is an affective or emotional response toward various facet of one's job. This definition implies job satisfaction is not a unitary concept. Rather, a person can be relatively satisfied with one aspect of his or her job and dissatisfied with one/more other aspects". Kepuasan kerja adalah respon perasaan atau emosional seseorang terhadap berbagai aspek pekerjaan. Seseorang dapat relatif puas dengan salah satu aspek pekerjaan, tetapi tidak puas dengan aspek lainnya. Kepuasan kerja di sini dapat diartikan sebagai terpenuhinya respons perasaan atau emosional seseorang terhadap berbagai aspek pekerjaan yang dirasakan dalam lingkungan kerja dan pengalaman yang didapat secara menyenangkan atau tidak menyenangkan. Colquitt, et.al. (2011: 105) mendefinisikan, "job satisfaction is defined as apleasurable emotional state resulting form the appraisal of one's job on job experiences. In the word, it represent how you feel about your job and what you think about your job". Kepuasaan kerja didefinisikan sebagai emosi atau perasaan menyenangkan atau tidak menyenangkan terhadap hasil penilaian suatu pekerjaan dan pengalaman kerja. Anda dapat menggambarkan bagaimana perasaan anda tentang pekerjaan dan apa yang anda pikir tentang pekerjaan itu. Noe, et. al. (2012: 458) mendefinisikan, "job satisfaction define as a pleasurable feeling that results from the perception that one's job fulfills or allows for the fulfillment of one's important job values." Kepuasan kerja didefinisikan sebagai perasaan menyenangkan yang dihasilkan dari persepsi bahwa pekerjaan seseorang memenuhi atau memungkinkan untuk pemenuhan nilai-nilai pekerjaan seseorang yang penting. Colquitt, et. al. (2015:100), juga menyodorkan beberapa aspek terkait, dalam 'The Value-Percept Theory of Job Satisfaction' antara lain, 
"value-percept theory also suggests that people evaluate job satisfaction according to specific "facet" af the job. After all, "job" isn't one thing-it's collection of task, relationship, and reward. The most common facets that employee consider in judging their job satisfaction appear includes that "wants vs have" calculations that drive satisfaction with pay, promotions, supervision, cowokers, and the work it self. The figure also shows how satisfaction with those five facets adds together to create "overall job satisfaction", shows that employee might be satisfied for all kinds of reasons". Teori nilai mengatakan bahwa, persepsi orang tentang kepuasan kerja diperoleh dengan mengevaluasi segi spesifik dari pekerjaan yakni adanya pertentangan perasaan tentang apa yang inginkan dengan apa yang dimiliki. Perbedaan antara keinginan dan pemenuhan keinginan itu terjadi dalam hal; gaji, promosi, supervisi, rekan kerja dan pekerjaan itu sendiri. Ke-5 (lima) segi tersebut merupakan keseluruhan dari aspek kepuasan kerja karyawan.

Berdasarkan definisi konsep yang telah diuraikan tersebut di atas dapat disintesiskan bahwa kepuasan kerja adalah respon perasaan senang atau tidak senang yang dialami seseorang terhadap pekerjaan dan pengalaman kerjanya dalam sebuah organisasi, dengan indikator: (1) perasaan terhadap pekerjaan, (2) perasaan terhadap gaji, (3) perasaan terhadap kesempatan promosi, (4) perasaan terhadap supervisi, (5) perasaan terhadap rekan kerja.

\section{METODE}

Penelitian ini dilakukan untuk menguji pengaruh langsung; 1) LMX terhadap produktivitas, 2) Kepuasan kerja terhadap produktivitas, 3) LMX terhadap kepuasan kerja. penelitian menggunakan metode survey dengan pendekatan teknik analisis jalur. Penelitian dilaksanakan di Sekolah Dasar Swasta Katolik di Wilayah Jakarta Pusat dengan populasi terjangkau sebanyak 248 guru dan sampel sebanyak 153 guru. Analisis data untuk pengujian hipotesis dilakukan dengan menggunakan teknik analisis jalur untuk menjelaskan pengaruh antara variabel-variabel penelitian. Sebelum dilaksanakan analisis jalur, uji signifikan regresi dan uji lineritas regresi sebagai prasyarat uji statistik dilakukan pengujian penormalan dat dari masing-masing variable penelitian dengan Uji Liliefors. Statistik inferensial digunakan untuk menguji hipotesis tentang pengaruh antar variabell dengan menggunakan teknik analisis jalur. 


\section{HASIL DAN PEMBAHASAN}

\section{Pengaruh Leader Member Exchange (LMX) terhadap Produktivitas}

Dari hasil pengujian hipotesis pertama dapat disimpulkan bahwa terdapat pengaruh langsung positif Leader Member Exchange (LMX) terhadap Produktivitas dengan nilai koefisien korelasi sebesar 0,427 dan nilai koefisien jalur sebesar 0,350. Ini memberikan makna bahwa Leader Member Exchange berpengaruh langsung terhadap produktivitas. Hess dan Orthmann (2012: 463), menjelaskan, "productivity is converting resources to achieve results efficiently and effectively. Productivity measures results gained from a specific amount of effort. An efficient use of resources alone may not be effective or meet a desired need. An effective use of resources may not be efficient or sufficient in overall impact. Productivity planning helps balance efficiency and effectiveness guided by an overall desire for value". Produktivitas adalah konversi sumber daya untuk mencapai hasil secara efisien dan efektif. Produktivitas mengukur perolehan hasil yang spesifik dari sejumlah usaha. Perencanaan dan penggunaan sumber daya yang efisien dan efektif secara seimbang dapat berdampak pada nilai produktivitas secara keseluruhan. Allen, Plunkett, Attner (2013: 130) mengatakan, productivity is the relationship between the amount of input needed to produce a given amount of output and the output it self. Productivity is usually expressed as the ratio of inputs to outputs. Output (inputs produce)/Input (hours of human labor, machining time, or dollar invested $)=$ Productivity Index (PI). Such a ratio is a measure of efficiency that can be used to make comparisons and indentify trends. Productivity can be improve by increasing the amount of output generated by a fixed amount of input, or reducing the amount of input required to generate a fixed amount of output or a combination of both approaches. Produktivitas adalah hubungan antara jumlah masukan yang diperlukan untuk menghasilkan sejumlah output tertentu. Produktivitas biasanya dinyatakan sebagai rasio input ke output. Output (input produksi)/input (jam kerja manusia, waktu, atau dolar yang diinvestasikan) $=$ Indeks Produktivitas (PI). Rasio tersebut adalah suatu ukuran efisiensi yang dapat digunakan untuk membuat perbandingan dan mengidentifikasi hal-hal yang dapat meningkatkan jumlah output yang dihasilkan oleh jumlah yang tetap dari input, atau mengurangi jumlah input yang diperlukan untuk menghasilkan jumlah yang tetap produksi atau kombinasi dari kedua pendekatan tersebut.

Hasil penelitian ini senada dengan pendapat Achua, dan Lussier (2010: 213) yang mengatakan bahwa, "the quality of LMX affect employee' work ethics, productitvity, satisfaction and perception". Kualitas LMX mempengaruhi etos kerja, produktitvitas, kepuasan dan persepsi karyawan. Demikian juga Lunenburg (www.nationalforum.com (2010: 3), mengatakan," an important implication of the leader-member exchange theory is that the quality of the relationship between the leader and each group member has important job consequences. Specifically, the research supporting the LMX theory indicates that subordinates with in-group status with their leaders will have higher productivity...." Satu implikasi penting dari teori pertukaran pemimpin dan anggota adalah mutu dari hubungan di antara pemimpin dan setiap anggota itu mempunyai konsekwensi pada pekerjaan. Secara terperinci, penelitian ini mendukung teori LMX bahwa hubungan yang berkualitas antara pemimpin dan bawahan yang termasuk "orang dalam" akan menyebabkan bawahan mempunyai produktivitas yang lebih tinggi.

\section{Pengaruh Kepuasan Kerja terhadap Produktivitas}

Dari hasil pengujian hipotesis kedua dapat disimpulkan bahwa terdapat pengaruh langsung positif kepuasan kerja terhadap produktivitas dengan nilai koefisien korelasi sebesar 0,352 dan nilai koefisien jalur sebesar 0,238. Ini memberikan makna 
bahwa kepuasan kerja berpengaruh langsung terhadap produktivitas. Kreitner dan Kinicki (2010:170), menguraikan, "job satisfaction is an affective or emotional response toward various facet of one's job. This definition implies job satisfaction is not a unitary concept. Rather, a person can be relatively satisfied with one aspect of his or her job and dissatisfied with one/more other aspects". Kepuasan kerja adalah respon perasaan atau emosional seseorang terhadap berbagai aspek pekerjaan. Seseorang dapat relatif puas dengan salah satu aspek pekerjaan, tetapi tidak puas dengan aspek lainnya. Kepuasan kerja di sini dapat diartikan sebagai terpenuhinya respons perasaan atau emosional seseorang terhadap berbagai aspek pekerjaan yang dirasakan dalam lingkungan kerja dan pengalaman yang didapat secara menyenangkan atau tidak menyenangkan. Colquitt, et.al. (2011: 105) mendefinisikan, "job satisfaction is defined as apleasurable emotional state resulting form the appraisal of one's job on job experiences. In the word, it represent how you feel about your job and what you think about your job". Kepuasaan kerja didefinisikan sebagai emosi atau perasaan menyenangkan atau tidak menyenangkan terhadap hasil penilaian suatu pekerjaan dan pengalaman kerja. Anda dapat menggambarkan bagaimana perasaan anda tentang pekerjaan dan apa yang anda pikir tentang pekerjaan itu.

Temuan penelitian ini sesuai dengan teori yang dikemukakan oleh Robbins dan Cuolter, (2012: 396) bahwa, "job satisfaction positively influences productivity,..". Kepuasan kerja secara positif mempengaruhi produktivitas. Singh dan Jain (mujournal. mewaruniversity.in) (2013: 105) mengatakan bahwa, "employee job satisfaction is essential to face the dynamic and ever-increasing challenges of maintaining productivity of the organization by keeping their workforce constantly engaged..." Kepuasan kerja karyawan penting untuk menghadapi tantangan yang dinamis dan senantiasa meningkatkan serta memelihara produktivitas organisasi dengan mempertahankan kekuatan dan keterlibatan kerja karyawan secara konstan.

\section{Pengaruh Leader Member Exchange (LMX) terhadap Kepuasan Kerja}

Dari hasil pengujian hipotesis ketiga dapat disimpulkan bahwa terdapat pengaruh langsung positif LMX terhadap kepuasan kerja dengan nilai koefisien korelasi sebesar 0,325 dan nilai koefisien jalur sebesar 0,325. Ini berarti LMX berpengaruh langsung terhadap kepuasan kerja. Yukl (2010: 122) menjelaskan, "Leader-Member Exchange theory describes the role-making processes between a leader and each individual subordinate and the exchange relationship that develops over time." Teori pertukaran antara pemimpin - anggota menjelaskan tentang pembuatan peran di antara satu pemimpin dan masing-masing orang bawahan yang melampaui batas waktu. Menurut Graen dan Uhl-Bien, (mario.gsia.cmu.edu), (1995), menegaskan, "development of LMX is based on the characteristics of the working relationship as opposed to a personal or friendship relationship, and this trust, respect, and mutual obligation refer specifically to the individuals' assessments of each other in terms of their professional capabilities and behaviors. LMX dapat dibangun oleh pemimpin dan anggota dalam relasi kerja berdasarkan rasa percaya, sikap hormat kepada kemampuan profesional dan kewajiban timbal balik satu sama lain. Rastgar, Pourebrahimi, Davoudi (www.pbr.co.in) (2012) menjelaskan, Leader-Member Exchange Theory (LMX) is a leadership theory that focuses on the two-way relationship between a supervisor (manager) and each of their subordinates (employees) and contributes to increasing organizational success by creating positive relations between the leader and subordinate. Teori Leader Member Exchange (LMX) adalah teori kepemimpinan yang berfokus pada hubungan dua arah antara atasan (manajer) dan masing-masing bawahan (karyawan) memberikan kontribusi untuk meningkatkan keberhasilan organisasi dengan menciptakan hubungan positif antara pemimpin dan bawahan. 
Hasil penelitian ini didukung oleh teori yang dikemukakan oleh George, dan Jones (2012: 353) bahwa, in these dyads, the subordinate helps the leader, and the leader helps the subordinate, and each has substantial influence over the other. the leader spends a lot of time with the subordinate, who is given latitude or freedom to use his or her own judgment on the job. in turn, the subordinate tends to be satisfied and to perform at a high level. Dalam hubungan dua arah antara pemimpin dan bawahan, masing-masing mempunyai pengaruh substansiil satu terhadap yang lain. Pemimpin memberikan waktu dan kebebasan kepada bawahan untuk dipergunakan semestinya, bawahan yang mengunakkannya dengan baik akan merasa dipuaskan. Rasouli dan Haghtaali (www.graduate.au.edu/Journal) (2006-2009: 64-65) juga mengatakan, "when a manager enhance his/her relationship quality with their employees through maintaining a good work environment, respecting others' emotions, creating trust feeling, making an open and effective connections, special consideration and attentions, providing training, supporting employees, and transferring confidence feeling to employees; then he/she can be hopeful that at least, they removed the potential barriers to employees' job satisfaction. When the employees' external needs are fulfilled, then there will be a high-quality relationship between a manager and an employee, and the possibility that the manager respect employees effort, allocate responsibilities, and creates job promotion opportunities will be increased. On the other hand, if the employees' internal needs are fulfilled, the possibility that employees obtain higher job satisfaction from their job, will increase". Jika kepala sekolah mau membangun hubungan dengan gurunya yang positif dan berkualitas tinggi maka kepala sekolah perlu memenuhi kebutuhan eksternal dan internal setiap gurunya. Kebutuhan eksternal guru seperti: menghormati upaya guru, memberikan tanggung jawab, dan menciptakan kesempatan untuk meningkatkan promosi kerja; dan kebutuhan internal guru seperti: menciptakan rasa kepercayaan, membangun hubungan yang terbuka dan efektif, membuat pertimbangan khusus terhadap masing-masing guru, memberi perhatian, memberikan pelatihan, dan mendukung guru dalam seluruh tugasnya. Jika kebutuhan eksternal dan internal guru terpenuhi, maka guru akan berusaha untuk meningkatkan kualitas pekerjaan serta mendapat gaji yang tinggi. Dengan itu guru akan mendapatkan kepuasan kerja yang lebih tinggi.

\section{PENUTUP}

Kesimpulan. Berdasarkan temuan penelitian ini dapat disimpulkan bahwa: (1) Leader Member Exchange (LMX) berpengaruh langsung positif terhadap produktivitas. Artinya peningkatan kualitas LMX yang dirasakan guru mengakibatkan peningkatan produktivitas guru Sekolah Dasar Swasta Katolik di Wilayah Jakarta Pusat (2) Kepuasan kerja guru berpengaruh langsung positif terhadap produktivitas. Artinya peningkatan kepuasan kerja mengakibatkan peningkatkan produktivitas guru Sekolah Dasar Swasta Katolik di Wilayah Jakarta Pusat (3) Leader Member Exchange (LMX) berpengaruh langsung positif terhadap kepuasan kerja. Artinya peningkatan LMX mengakibatkan peningkatan kepuasan kerja guru Sekolah Dasar Swasta Katolik di Wilayah Jakarta Pusat.

Saran. Berdasarkan hasil penelitian dapat dikemukakan beberapa saran. Majelis Pendidikan Katolik di Jakarta Pusat, sesuai dengan perannya perlu memperhatikan peningkatan kualitas LMX dan kepuasan kerja dengan memfasilitasi para guru dan kepala sekolah untuk mengembangkan kompetensi dirinya melalui berbagai macam program pendidikan, pelatihan dan pendampingan serta kegiatan lain. Melalui kegiatan tersebut diharapkan dapat mendorong guru untuk melaksanakan pembelajaran yang 
berkualitas secara efektif dan efisien sehingga produktivitas guru dapat meningkat. Yayasan Pendidikan Katolik di Wilayah ini, perlu menjawab permasalahan yang dihadapi para guru secara memadai untuk mendukung terwujudnya kepuasan kerja guru, sehingga guru yang akan mengeksplorasi seluruh kemampuannya untuk menunjukkan produktivitas yang tinggi. Kepala Sekolah, hendaknya dapat mengupayakan kualitas LMX yang baik dengan setiap guru, dan memperhatikan perwujudkan dimensi-dimensi penting dari kepuasan kerja guru. Kualitas LMX yang baik dan kepuasan kerja guru yang tinggi akan memungkinkan guru-guru dapat memiliki produktivitas yang tinggi. Para guru, hendaknya dapat berusaha secara optimal untuk terus membangun hubungan dua arah yang positif dengan kepala sekolah dan mengupayakan kepuasan kerja dalam dirinya untuk menghasilkan kerja yang produktif. Peneliti lain, agar dapat menindaklanjuti penelitian-penelitian serupa dengan mengembangkan variabel-variabel bebas dan cakupan wilayah penelitian lainnya karena ruang lingkup penelitian ini hanya terbatas pada LMX dan kepuasan kerja guru. 


\section{DAFTAR RUJUKAN}

Achua, Christopher F. D. B. A, Robert N. Lussier. Effective Leadership, 5e, (Canada: South Western, Cengage Learning, 2013.

Allen, Gemmy S, Warren R. Plunkett, Raymond F. Attner. Management, An Approach to Customer Expectations. Canada: South Western, Cengage Learning, 2013.

Colquitt, Jason A, Jeffery A. Lepine, Michael J. Wesson. Organizational Behavior Improving Performance and Commitment in The Workplace. Second Edition. New York: McGraw Hill, 2011.

,Organizational Behavior, Improving Performance $\mathcal{E}$ Commitment in the Workplace. $4^{\text {th }}$ Edition. New York: McGraw-Hill, 2015.

George B. \& Mary Uhl-Bien. "Relationship-Based Approach to Leadership: Graen Development Of Leader-Member Exchange (LMX) Theory of Leadership Over 25 Years: Applying A Multi-Level Multi-Domain Perspective," Leadership Quarterly, Vol. 6 (2), 1995, h. 227. http://mario.gsia.cmu.edu/micro_2009/GraenLMX.pdf, (diakses 10 November 2014).

Hess, Karen Matison, Christine Hess Orthmann. Management And Supervision in Law Enforcement USA: Delmar, Cengage Learning, 2012.

http://eprints.undip.ac.id/234/1/pp-no-74-tahun-2008_guru.pdf. (diakses 3

November 2014)

http://lenterakecil.com/sekolah-swasta-rawan-kekurangan-siswa/ (diakses 3 November 2014).

http://nasional.kompas.com./read/2012/04/17/12214022/Indeks.Pembangunan\%M anusia \%20 Indonesia\%20Rendah. (diakses 3 November 2014).

http://repository.upi.edu/10785/2/t_pmp_0909896_chapter1.pdf $\quad$ (diakses 3 November 2014).

http://www.mediapendidikan.info/2010/09/permendiknas-nomor-13-tahun2007.html (diakses 3 November 2014).

http://www.srie.org/2013/02/hasil-uka-dan-ukg-kompetensi-guru-lebih.html, (diakses 3 November 2014)

http://perdesaansehat.com/2014/07/24/ipm-indonesia-stagnan-di-peringkat-108perdesaansehat-com/\#respond (diakses 3 November 2014).

Ivancevich, John M. Robert Konopaske, Michael T. Matteson. Organizational Behavior and Management. New York: McGraw-Hill Companies, 2008.

Kreitner, Robert \& Angelo Kinicki. Organizational Behavior, 9th Edition. New York: McGraw-Hill, 2010. 
Lepak, David Mary Gowan. Human Resources Management, Managing Employees for Competitive Advantage. New Jersey: Pearson Education Inc, 2010.

Ling Hsieh, Hsiow. "Building Employees Organizational Commitment with LMX: the Mediating Role of Supervisor Support." I-Shou University Kaohsiung, Taiwan, Global Journal of Engineering Education, Vol.14 (3), 2012. http://www.wiete.com.au/journals/GJEE/Publish/vol14no3/07-Hsieh-HH.pdf (diakses 8 November 2014).

Newstrom, John W. Organizational Behavior: Human Behavior at Work, $13^{\text {th }}$ Edition. New York: McGraw-Hill, 2011.

Rastgar, Abbas Ali, Nina Pourebrahimi, Seyed Mehdi Mousavi Davoudi. "LeaderMember Exchange and Organizational Citizenship Behavior: A Survey in Iran's Food Industry," Pacific Business Review International, Vol. 5 (5), November, 2012. http://www.pbr.co.in/Vol-5\%20Iss-5/2.pdf/ (diakses 8 November 2014).

Sedarmayanti. Sumber Daya Manusia dan Produktivitas Kerja. Bandung: CV Mandar Maju, 2009.

Yukl, Gary. Leadership in Organization, Seventh Edition. New Jersey: Pearson Education Inc, 2010. 